ORIGINAL ARTICLE

\title{
Risk factors for hamstring injuries in community level Australian football
}

\author{
B J Gabbe, C F Finch, K L Bennell, H Wajswelner
}

Br J Sports Med 2005;39:106-1 10. doi: 10.1136/bjsm.2003.011197

See end of article for authors' affiliations

.....................

Correspondence to: Dr Gabbe, Monash University, Epidemiology and Preventive Medicine, Central and Eastern Clinical School, Alfred Hospital, Commercial Road, Prahran, Victoria 3181. Australia; Belinda.gabbe@ med.monash.edu.au

Accepted 4 February 2004

\begin{abstract}
Objectives: To identify risk factors for hamstring injury at the community level of Australian football. Methods: A total of 126 community level Australian football players participated in this prospective cohort study. To provide baseline measurements, they completed a questionnaire and had a musculoskeletal screen during the 2000 preseason. All were monitored over the season. Injury surveillance and exposure data were collected for the full season. Survival analysis was used to identify independent predictors of hamstring injury.

Results: A hamstring injury was the first injury of the season in 20 players (16\%). After adjustment for exposure, increasing age and decreased quadriceps flexibility were identified as significant independent predictors of the time to sustaining a hamstring injury. Older age ( $\geqslant 23$ years) was associated with an increased risk of hamstring injury (RR 3.8; $95 \%$ confidence interval $(\mathrm{CI}) 1.1$ to $14.0 ; p=0.044$ ). Players with increased quadriceps flexibility (as measured by the modified Thomas test) were less likely to sustain a hamstring injury (RR $0.3 ; 95 \% \mathrm{Cl} 0.1$ to $0.8 ; \mathrm{p}=0.022$ ).

Conclusions: The findings of this study can be used in the development of hamstring injury prevention strategies and to identify Australian football players at increased risk of hamstring injury.
\end{abstract}

$\mathrm{H}$ amstring injuries are common in sprinting, dancing, martial arts, hockey, and kicking sports such as soccer, American football, and Australian football. ${ }^{1-7}$ These injuries are often recurrent and result in considerable costs such as missed training time, unavailability for competition, and treatment. They have long been recognised as a priority for efforts at prevention. Studies on their causes date back to the $1970 \mathrm{~s},{ }^{8}$ and many studies have been published since that have discussed the mechanisms of hamstring injury, potential risk factors, and rehabilitation of these injuries. ${ }^{24} 59-11$ Although intrinsic factors such as age, injury history, ethnicity, hamstring flexibility, and hamstring muscle strength have been investigated in prospective studies, the findings have been contradictory, used laboratory based testing, or identified irreversible risk factors. ${ }^{32-17}$ Other proposed risk factors such as warm up habits ${ }^{9}$ and neural mobility ${ }^{18}$ have not been investigated at all or only using a retrospective study design respectively.

Despite its classification as a body contact sport, Australian football requires frequent sprinting and kicking, and there is a high incidence of hamstring injury. ${ }^{67}$ Prevention of this injury is a priority for this sport, ${ }^{12}{ }^{13} 19$ making participants ideal subjects for the study of risk factors. Therefore the aim of this study was to identify risk factors for hamstring injury in community level Australian football players.

\section{METHODS}

\section{Study design and participants}

The identification of risk factors for hamstring injury formed part of a larger study to establish risk factors for lower extremity injuries at the community level of Australian football. The methodology is published elsewhere ${ }^{20}$ and only a summary is provided here.

Players from four adult Victorian Amateur Football Association clubs were recruited for this prospective cohort study during the 2000 preseason. All players training at the time of baseline assessment were invited to participate and were only excluded if they were currently injured and therefore unable to complete the measurement process.
Written informed consent was obtained from all subjects, and ethics approval was granted by the University of Melbourne human research ethics committee.

\section{Procedures}

Once recruited, all subjects were required to complete the baseline measurement procedures. All testing was completed in the three weeks before the start of preseason practice games and carried out at the clubs' training venues. Each subject had a series of musculoskeletal screening tests and was required to complete a questionnaire.

\section{Questionnaire}

Table 1 lists the information collected by questionnaire. The questionnaire aimed to capture information about: previously proposed hamstring injury risk and protective habits, such as warming up and use of thermal shorts; previously identified hamstring injury risk factors, such as age and injury history; other factors that could affect hamstring injury risk, such as level of competition and participation in other sports. Questionnaire items ${ }^{21}$ were shown to be reliable (level of agreement, $\kappa>0.8$ ), was and the validity of injury history recall $^{22}$ was established.

\section{Musculoskeletal assessment}

Tests were selected on the basis of previous research, common clinical use for the assessment of hamstring injuries, ability to test at a variety of training locations, and requiring inexpensive equipment for testing. ${ }^{13} 1823-26$ Intertester and intratester reliability were established if not previously described. ${ }^{27}$ Table 2 provides an overview of the musculoskeletal tests selected to measure the potential hamstring injury risk factors of hamstrings flexibility, quadriceps flexibility, iliopsoas flexibility, lumbar spine range of movement, dorsiflexion range of movement, hip rotation range of movement, and neural mobility.

All musculoskeletal screening was performed by four trained testers (three qualified physiotherapists and one postgraduate student with experience in musculoskeletal 
Table 1 Potential risk factors for hamstring injury in community level Australian football

\begin{tabular}{|c|c|}
\hline Questionnaire item & Method of measurement \\
\hline Age & Years \\
\hline Playing experience & Years of competition experience \\
\hline Injury history & $\begin{array}{l}\text { History of sustaining a hamstring injury in } \\
\text { previous season }\end{array}$ \\
\hline Playing position & Position played on the field most regularly \\
\hline Level of competition & $\begin{array}{l}\text { Senior (highest grade) or reserve (second } \\
\text { grade) }\end{array}$ \\
\hline $\begin{array}{l}\text { Off season training } \\
\text { habits }\end{array}$ & $\begin{array}{l}\text { Sports played regularly } \\
\text { Frequency and hours per week spent running, } \\
\text { swimming, cycling, stretching, and weight } \\
\text { training }\end{array}$ \\
\hline Preseason training & Sports played regularly \\
\hline & $\begin{array}{l}\text { Frequency and hours per week spent running, } \\
\text { swimming, cycling, stretching, and weight } \\
\text { training }\end{array}$ \\
\hline Season training habits & Sports played regularly \\
\hline & $\begin{array}{l}\text { Frequency and hours per week spent running, } \\
\text { swimming, cycling, stretching, and weight } \\
\text { training }\end{array}$ \\
\hline $\begin{array}{l}\text { Protective equipment } \\
\text { use }\end{array}$ & $\begin{array}{l}\text { Frequency of use of thermal shorts at training } \\
\text { and during matches }\end{array}$ \\
\hline Warm up habits & $\begin{array}{l}\text { Frequency of participation in warm up at } \\
\text { training sessions and before matches }\end{array}$ \\
\hline Cool down habits & $\begin{array}{l}\text { Frequency of participation in cool down at } \\
\text { training sessions and after matches }\end{array}$ \\
\hline \multirow[t]{2}{*}{ Smoking history } & Current smoking status \\
\hline & Number of cigarettes smoked per day \\
\hline
\end{tabular}

screening) and performed after the club's standard warm up of 5-10 minutes of low intensity cardiovascular activity and lower extremity stretches. The methodology used was consistent with protocols used to establish reliability. ${ }^{25} 28$

\section{Outcome measures}

Data on injury surveillance and exposure (hours of match and training participation) were collected prospectively over the course of the season using previously published methods. ${ }^{7}$ Injuries resulting in missed participation time and/or treatment from a health professional were captured by the surveillance system. Details on the mechanism, nature, specific body region, and provisional diagnosis were collected by the club's physiotherapist or medical staff. Exposure time was collected by a member of the club's coaching staff. The major outcome of interest was a hamstring injury diagnosed by physical examination using the criteria: ${ }^{5} 290$

- sudden onset posterior thigh pain;

- tenderness on palpation;

- with or without pain on stretch of the hamstring muscle group;

- with or without pain on contraction of the hamstring muscle group.

\section{Data management and analysis}

Injury, exposure, and baseline assessment data were coded and double entered on a personal computer. Statistical analyses were performed using SPSS for Macintosh (version 10) (SPSS Inc, Chicago, Illinois, USA).

Cox proportional hazards regression ${ }^{31}$ was used to identify independent predictors of hamstring injury. The time to first injury was considered important because of the potential for baseline assessment factors to change after injury. Therefore if the hamstring injury was the subject's first injury, it was considered to be a hamstring case. All other subjects were considered censored, with the point of censorship defined as the end of the season for injury-free players or the time of
Table 2 Musculoskeletal screening tests used to measure potential hamstring injury risk factors in community level Australian football

\begin{tabular}{|c|c|}
\hline Potential risk factor & Musculoskeletal screening test \\
\hline Hamstring flexibility & $\begin{array}{l}\text { Active knee extension test }{ }^{2427} \\
\text { Passive straight leg raise test }{ }^{2738}\end{array}$ \\
\hline $\begin{array}{l}\text { General lower extremity } \\
\text { flexibility }\end{array}$ & Sit and reach test ${ }^{23} 39$ \\
\hline Quadriceps flexibility & Modified Thomas test ${ }^{25} 27$ \\
\hline Iliopsoas flexibility & Modified Thomas test ${ }^{25} 27$ \\
\hline Dorsiflexion ROM & Dorsiflexion lunge test ${ }^{28}$ \\
\hline Neural mobility & Active slump test ${ }^{1827}$ \\
\hline Lumbar spine ROM & Extension ROM in standing position ${ }^{26} 27$ \\
\hline Hip rotation $\mathrm{ROM}$ & $\begin{array}{l}\text { Active hip internal and external ROM in } \\
\text { supine position }{ }^{27}\end{array}$ \\
\hline
\end{tabular}

injury for those for whom a hamstring injury was not the first sustained. Days to injury was chosen as the time variable. The model was adjusted for exposure (total training and match time). Each continuous variable was dichotomised (according to the mean or median) for analysis to separate the cohort into groups based on test performance. The model selection strategy was that recommended by Collett. ${ }^{31}$ The adjusted relative risk (RR) and 95\% confidence interval (CI) were calculated, and Kaplan-Meier curves used to compare subgroups.

\section{RESULTS}

Of a possible 148 players, $126(85.1 \%)$ participated in this project. Twenty (15.9\%) sustained a total of 26 hamstring injuries during the season, an incidence of 4.0 injuries per 1000 player hours. For all players, a hamstring injury was the first sustained for the season. Most hamstring injuries were sustained during competition $(76.9 \%)$, the remainder occurring during club training sessions. Rapid acceleration during running or sprinting was the primary mechanism (80.8\%). The remainder occurred when the player kicked the football $(19.2 \%)$.

Six variables were identified as independent predictors of the time to sustaining a hamstring injury through the survival analysis (table 3 ).

Table 3 Independent predictors of time to sustaining a hamstring injury in community level Australian football

\begin{tabular}{|c|c|c|}
\hline Variable & $\operatorname{RR}(95 \% \mathrm{Cl})$ & p Value \\
\hline \multicolumn{3}{|l|}{ Quadriceps flexibility } \\
\hline $\begin{array}{l}\text { Less flexible ( } \leqslant 51^{\circ} \text { knee flexion) } \\
\text { (reference) }\end{array}$ & - & \\
\hline More flexible ( $>51^{\circ}$ knee flexion) & $0.3(0.1$ to 0.8$)$ & 0.022 \\
\hline \multicolumn{3}{|l|}{ Age } \\
\hline$<23$ years (reference) & - & \\
\hline$\geqslant 23$ years & $3.8(1.1$ to 14.0$)$ & 0.044 \\
\hline \multicolumn{3}{|l|}{ Active knee extension ROM } \\
\hline $\begin{array}{l}\text { More flexible ( } \leqslant 27^{\circ} \text { knee flexion) } \\
\text { (reference) }\end{array}$ & - & \\
\hline Less flexible (>27 $>27^{\circ}$ knee flexion) & $2.8(0.9$ to 8.5$)$ & 0.076 \\
\hline \multicolumn{3}{|l|}{ Frequency of off season running } \\
\hline None (reference) & - & \\
\hline$\geqslant 1$ session a week & $0.4(0.1$ to 1.3$)$ & 0.140 \\
\hline \multicolumn{3}{|l|}{ Height } \\
\hline$\leqslant 181 \mathrm{~cm}$ (reference) & - & \\
\hline$>181 \mathrm{~cm}$ & $1.7(0.5$ to 5.7$)$ & 0.382 \\
\hline \multicolumn{3}{|l|}{ Slump ROM } \\
\hline $\begin{array}{l}\text { More flexible ( } \leqslant 15^{\circ} \text { knee flexion) } \\
\text { (reference) }\end{array}$ & - & \\
\hline Less flexible (>15 $>$ knee flexion) & $0.6(0.2$ to 1.9$)$ & 0.430 \\
\hline Total exposure hours & $1.0(0.9$ to 1.0$)$ & 0.667 \\
\hline
\end{tabular}




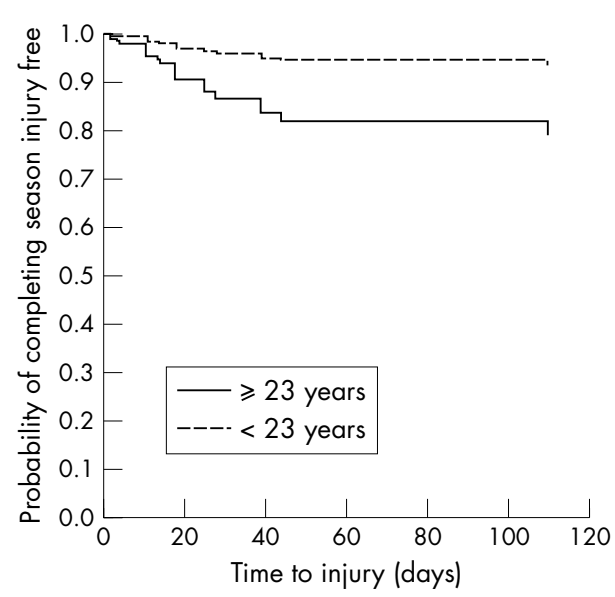

Figure 1 Kaplan-Meier survival curves for time to sustaining a hamstring injury according to age category.

Figure 1 shows the Kaplan-Meier curve for time to first hamstring injury according to age group. There was a significantly reduced probability of remaining hamstring injury free for players aged 23 years or more compared with the younger group.

A similar relation is shown for quadriceps flexibility, with players in the least flexible group $\left(<52^{\circ}\right.$ knee flexion $)$ having a decreased probability of completing the season without sustaining a hamstring injury (fig 2).

None of the remaining variables showed significant relative risks (table 3), although hamstring flexibility, as assessed by the active knee extension test, approached significance $(\mathrm{p}=0.076)$.

\section{DISCUSSION}

This prospective cohort study is the first to investigate an extensive list of potential risk factors for hamstring injury in community level Australian football players. Using a questionnaire and simple clinical measures that can be performed in a variety of locations with minimal equipment, a number of independent predictors of hamstring injury were identified. Age and quadriceps flexibility were significant independent predictors of hamstring injury in this cohort of players, and hamstring flexibility approached significance.

In this study, players aged 23 years or more were almost four times as likely as younger players to sustain a hamstring

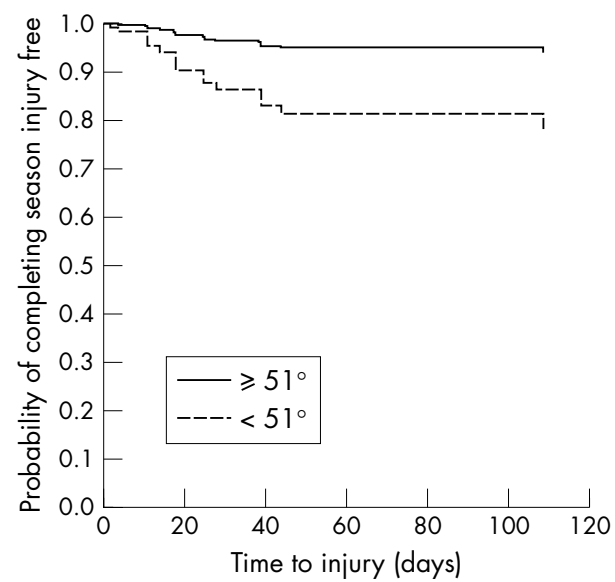

Figure 2 Kaplan-Meier curves for time to sustaining a hamstring injury according to category of quadriceps flexibility. injury first during the season, a finding similar to two studies of elite Australian football players. ${ }^{12}{ }^{17}$ Other prospective studies of risk factors for hamstring injury, including those performed in other sports, have not studied age as a risk factor. ${ }^{314-16}$

As the body ages, there is a reduction in the cross sectional area of skeletal muscle and an increase in the non-muscle connective tissue. A reduction in type II muscle fibre size and skeletal muscle fibre number contributes to the loss of cross sectional area and skeletal muscle mass. As the force that a muscle can generate is proportional to the cross sectional area, a reduction in muscle strength occurs with the changes described..$^{32}$ These changes, combined with age related denervation of muscle fibres, ${ }^{33}$ may increase the risk of hamstring injury due to the workload placed on the hamstrings muscle group during Australian football. Although the presence of subtle age related changes in muscle may explain the elevated risk of hamstring injury in Australian football players, the age at which significant age related changes in skeletal muscle structure affect function in young adult athletes has not been determined.

Although age has previously been associated with hamstring injury risk, the finding of quadriceps flexibility as a significant independent predictor of hamstring injury is novel. Previous studies have not investigated the relation between quadriceps flexibility and the risk of hamstring injury despite a number of studies investigating quadriceps strength as a risk factor. ${ }^{13} 151634$ The mechanism by which increased quadriceps flexibility would protect against hamstring injury is not clear but may involve alteration in the mechanics of running and sprinting.

In this study, quadriceps flexibility was tested in the modified Thomas test position..$^{25}$ In this position, the hip is extended and the knee flexed with gravity. The test position mimics the terminal stance and pre-swing position of the leg during running and sprinting. At this point in the running cycle, the biarticular rectus femoris muscle of the quadriceps group is lengthened over both the hip and knee, and is acting eccentrically to arrest extension of the hip and flexion of the knee. ${ }^{35}$ As it stretches, the tendon of the rectus femoris absorbs energy, which is released during the active flexion of the hip and knee through mid to late swing, accelerating the forward movement of the leg. Before initial contact, the hamstrings must contract eccentrically, generating high torque, to decelerate the forward momentum of the tibia, increasing the load on the hamstrings and thereby increasing their susceptibility to injury. ${ }^{11}$ If the rectus femoris is very tight, there may be a rise in the passive elastic recoil of the tendon, increasing the acceleration of hip flexion and knee extension, which must be counteracted by the eccentrically contracting hamstrings. Therefore a greater load may be placed on the hamstring muscles, potentially increasing their chance of failure and the risk of injury.

Hamstring flexibility approached significance as a predictor of injury, but the remaining predictors in the final modelneural mobility, height, and off season running frequencydid not. A detailed discussion of the mechanisms by which these factors affect hamstring injury risk is not necessary.

Whether these results can be extrapolated to elite level Australian football or other sports is difficult to discern. There is a paucity of information comparing the characteristics of players from different levels of Australian football and therefore whether the findings would hold true for elite participants is uncertain. Most of the hamstring injuries in this group occurred during sprinting, an activity inherent to a number of sports. Consideration should be given to investigating these attributes as potential risk factors for hamstring injury in sprinting sports. 


\section{What is already known on this topic}

Prospective studies on a variety of potential risk factors for hamstring injury in sport are lacking. Previous studies of elite Australian football players have identified age, injury history, and aboriginality as predictors of hamstring injury.

This study has a number of strengths. The prospective design enabled the identification of potential causal relations, and a large number of potential risk factors were studied. All injuries resulting in missed participation time were captured by the surveillance system, and complete exposure data were collected for all 126 subjects. Sufficient information for the application of survival analysis methods was collected, enabling a more sophisticated approach to predicting the onset of hamstring injury. Rather than just comparing the injured with uninjured players, we considered the time to injury onset, and therefore adjustment for exposure time was possible.

Limitations to this study also exist and must be acknowledged. Hamstring injury was a relatively common event, with $16 \%$ of the cohort sustaining at least one. However, the number of cases in the multivariate modelling (20) was relatively small, limiting the power of the study and the ability to identify all but the largest effects. ${ }^{36}$ Although potential causal relations-that is, risk factors-could be identified using the prospective study design described, causality itself could not be established. Further studies are required to establish whether changes to the risk factors identified do result in altered hamstring injury risk.

The diagnosis of hamstring injury was made using clinical criteria, rather than imaging. Imaging, such as ultrasound or magnetic resonance, was not used because of the cost and the fact that these techniques are not yet standard protocol for diagnosis of hamstring injuries. Whether other injuries were included as hamstring injuries because of the diagnostic criteria used could not be determined. However, all diagnoses were made by qualified health professionals, and the findings of this study should hold true for injuries meeting the stated criteria.

The study could be considered a cluster design because of the recruitment of clubs from a single league. Potentially, the use of a cluster sample leads to a greater homogeneity of the population studied, further increasing the difficulty of identifying subtle causal relations. However, although this is a possibility, a similar study found the design effect to be close to one, suggesting no clustering. ${ }^{37}$ Therefore data were not analysed to account for a cluster effect.

The possibility of selection bias cannot be ignored, as not all players could be recruited at baseline because of injury and non-attendance at preseason training sessions. These groups may warrant further investigation to determine whether the risks of hamstring injury are different in those who sustain injuries in the preseason period and those who fail to complete a preseason training period.

\section{CONCLUSIONS}

This study was undertaken to address the paucity of information on risk factors for hamstring injury, particularly in Australian football at the community level where these injuries are both common and costly to clubs and players.

Overall, despite the relatively small number of hamstring injuries sustained by the cohort, the study identified a number of potential causal relations between baseline factors and hamstring injury. In particular, age and quadriceps flexibility were the only two significant independent predictors of time to hamstring injury. Although age itself
What this study adds

This study of community level Australian football players confirms increasing age, but also identifies decreased quadriceps flexibility, as independent predictors of hamstring injury in this group of athletes.

cannot be altered, the findings of this study clearly identify older Australian football players as a key target group for hamstring injury prevention activities, and suggest that further research to identify the mechanisms by which increasing age leads to greater hamstring injury risk is required. In contrast with age, quadriceps flexibility can be directly manipulated through stretching programmes in an attempt to reduce hamstring injury risk. However, identification of the best programmes to improve flexibility of this muscle group is necessary, and a randomised controlled trial of developed programmes is warranted to determine their effectiveness at reducing hamstring injury risk.

\section{ACKNOWLEDGEMENTS}

This research was partially supported by a grant from the Australian Physiotherapy Association (Victorian Branch). The staff and players of the Hampton Rovers Amateur Football Club, Old Haileybury Amateur Football Club, Ormond Amateur Football Club, and the Old Melburnians Football Club are sincerely thanked for their participation in this research. Dr Annie Solterbeck, from the Statistical Consulting Centre at the University of Melbourne, is thanked for her time and expertise. Dr Anthony Schache is also thanked for his thoughts and biomechanical expertise. BG was supported by a Public Health Research Fellowship from the National Health and Medical Research Council of Australia.

\section{Authors' affiliations}

B J Gabbe, Monash University, Melbourne, Victoria, Australia C F Finch, University of New South Wales, Sydney, Australia K L Bennell, University of Melbourne, Melbourne, Australia H Wajswelner, Australian Institute of Sport, Belconnen, ACT, Australia

Competing interests: none declared

\section{REFERENCES}

1 Askling $\mathrm{C}$, Lund $\mathrm{H}$, Saartok T, et al. Self-reported hamstring injuries in studentdancers. Scand J Med Sci Sport 2002;12:230-5.

2 Devlin L. Recurrent posterior thigh symptoms detrimental to performance in rugby union. Predisposing factors. Sports Med 2000;29:273-87.

3 Witvrouw E, Danneels L, Asselman P, et al. Muscle flexibility as a risk factor for developing muscle injuries in males professional soccer players. Am J Sports Med 2003;31:41-6.

4 Heiser T, Weber J, Sullivan G, et al. Prophylaxis and management of hamstring muscle injuries in intercollegiate football players. Am J Sports Med 1984; 12:368-70

5 Kroll P, Raya M. Hamstring muscles: an overview of anatomy, biomechanics and function, injury etiology, treatment and prevention. Crit Rev Phys Rehabil Med 1997;9:191-203.

6 Orchard J, Seward H. Epidemiology of injuries in the Australian Football League, seasons 1997-2000. Br J Sports Med 2002;36:39-45.

7 Gabbe B, Finch C, Wajswelner $\mathrm{H}$, et al. Australian football: injury profile at the community-level. J Sci Med Sport 2002;5:149-60.

8 Burkett L. Causative factors in hamstring strains. Med Sci Sport Ex 1970;2:39-42.

9 Worrell T. Factors associated with hamstring injuries. An approach to treatment and preventative measures. Sports Med 1994;17:338-45.

10 Coole W, Gieck J. An analysis of hamstring strains and their rehabilitation. J Orthop Sports Phys Ther 1987;9:77-85.

11 Stanton P, Purdam C. Hamstring injuries in sprinting: the role of eccentric exercise. J Orthop Sports Phys Ther 1989;10:343-9.

12 Orchard J. Intrinsic and extrinsic risk factors for muscle strains in Australian football. Am J Sports Med $2001 ; 29: 300-3$.

13 Orchard J, Marsden J, Lord S, et al. Preseason hamstring muscle weakness associated with hamstring muscle injury in Australian footballers. Am J Sports Med 1997;25:81-5.

14 Bennell K, Tully E, Harvey N. Does the toe-touch test predict hamstring injury in Australian Rules footballers? Aust J Physiother 1999;45:103-9. 
15 Bennell K, Waiswelner $\mathrm{H}$, Lew $\mathrm{P}$, et al. Isokinetic strength testing does not predict hamstring injury in Australian Rules footballers. Br J Sports Med 1998;32:309-14

16 Yamamoto T. Relationship between hamstring strains and leg muscle strength A follow-up study of collegiate track and field athletes. J Sports Med Phys Fitness 1993:33:194-9.

17 Verrall G, Slavotinek J, Barnes P, et al. Clinical risk factors for hamstring muscle strain injury: a prospective study with correlation of injury by magnetic resonance imaging. Br J Sports Med 2001;35:435-40.

18 Turl S, George K. Adverse neural tension: a factor in repetitive hamstring strain. J Orthop Sports Phys Ther 1998;27:16-21.

19 Gabbe B, Finch C, Wajswelner H, et al. Does community-level Australian football support injury prevention research? J Sci Med Sport 2003;6:231-6.

20 Gabbe B, Finch C, Waiswelner $\mathrm{H}$, et al. Predictors of lower extremity injuries at the community-level of Australian football. Clin J Sport Med 2004; 14:56-63.

21 Gabbe B. Risk factors for lower limb injuries at the community-level of Australian football. PhD thesis. Centre for Sports Medicine Research and Education, School of Physiotherapy. Melbourne: University of Melbourne, 2003.

22 Gabbe B, Finch C, Bennell K, et al. How valid is a self-reported 12-month sports injury history? Br J Sports Med 2003;37:545-7.

23 Bennell K, Malcolm S, Thomas S, et al. Risk factors for stress fractures in track and field athletes. Am J Sports Med 1996;24:810-18.

24 Gajdosik R, Lusin G. Hamstring muscle tightness: reliability of an Active-KneeExtension test. Phys Ther 1983;63:1085-90.

25 Harvey D. Assessment of the flexibility of elite athletes using the modified Thomas test. Br J Sports Med 1998;32:68-70.

26 Grant M, Purdam C, Schache A, et al. Pre-participation screening of athletes. Screening test protocols booklet. Canberra: Olympic Athlete Program, 1998.
27 Gabbe B, Bennell K, Wajswelner H, et al. The reliability of commonly used lower limb musculoskeletal screening tests. Physical Therapy in Sport 2004;5:90-7

28 Bennell K, Talbot $\mathrm{R}$, Wajswelner $\mathrm{H}$, et al. Intra-rater and inter-rater reliability of a weight-bearing lunge measure of ankle dorsiflexion. Aust J Physiother 1998:44:175-80

29 Baquie P. Could this be a hamstring injury? Aust Fam Physician 1999;28: 1053-4

30 Best T, Garrett W. Hamstring strains. Expediting return to play. Phys Sportsmed 1996:24:37-44.

31 Collett D. Modelling survival data in medical research. London: Chapman and Hall, 1994:72, 78-190.

32 Doherty T. The influence of aging and sex on skeletal muscle mass and strength. Curr Opin Clin Nutr Metab Care 2001 4:503-8.

33 Kirkendall D, Garrett W. The effects of aging and training on skeletal muscle. Am J Sports Med 1998;26:598-602.

34 Worrell T, Perrin D, Gansneder B, et al. Comparison of isokinetic strength and flexibility measures between hamstring injured and noninjured athletes. J Orthop Sports Phys Ther 1991;13:118-25.

35 Novachek T. The biomechanics of running. Gait Posture 1998;7:77-95.

36 Bahr R, Holme I. Risk factors for sports injuries: a methodological approach. Br J Sports Med 2003;37:384-92.

37 Finch C, Da Costa A, Stevenson M, et al. Sports injury experiences from the Western Australian sports injury cohort study. Aust N Z J Public Health 2002;26:462-7.

38 Butler D. Mobilisation of the nervous system. Melbourne: Churchill Livingstone, 1991:127-32.

39 Keogh J. The use of physical fitness scores and anthropometric data to predict selection in an Under-18 Australian Rules Football team. J Sci Med Sport 1999:2:125-33.

\section{ELECTRONIC PAGES}

\section{Online case reports}

7 he following electronic only articles are published in conjunction with this issue of BJSM (see also pages 69 and 101)

\section{Propagation of stress fracture of the patella}

M A A Crowther, A Mandal, P P Sarangi

Anterior knee pain in athletes is common and usually self limited. There should be a high index of suspicion and low threshold for special imaging in cases with acute onset and specific tenderness. The risk of propagation of stress fracture of the patella in athletes is highlighted. The case report presented illustrates the potential sequence of events.

(Br J Sports Med 2005;39:e6) http://bjsm.bmjjournals.com/ cgi/content/full/39/1/e6

\section{Kleine-Levin syndrome: a unique cause of fatigue in an athlete \\ C M J Conklin, J E Taunton}

Kleine-Levin syndrome (KLS) is a rare disorder characterised most notably, by periodic episodes of hypersomnolence and hyperphagia. Associated features of the disorder include a lack of concentration, mood changes, and anxiety. Laboratory tests may show slight changes in the electroencephalogram. However, clinical presentation and laboratory tests are normal during asymptomatic intervals. KLS most often presents in adolescent males, with complete recovery by the 3rd to 4th decade of life. Possible precipitating factors include excessive workload, febrile illness, and respiratory infections. Presented is a classical case of KLS in an adolescent male athlete. The patient's history, complete laboratory results, and symptoms are discussed. Possible treatments for this disorder are also mentioned, along with diagnostic criteria.

(Br J Sports Med 2005;39:e7) http://bjsm.bmjjournals.com/ cgi/content/full/39/1/e7

\section{False aneurysm of the common femoral vein in a footballer}

$M$ Karahan, S Isbir, F Baltacyoglu, et al

Traumatic false aneurysm of the femoral vein has never been reported in the English literature. The case is here reported of a footballer with a traumatic false aneurysm of the common femoral vein which was initially misdiagnosed as an arterial pseudoaneurysm. This is a very rare clinical condition, but this diagnosis should be among those considered for posttraumatic unexplained thigh pain after trauma.

(Br J Sports Med 2005;39:e8) http://bjsm.bmjjournals.com/ cgi/content/full/39/1/e8 